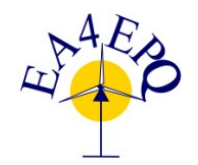

International Conference on Renewable Energies and Power Quality (ICREPQ'14)

Cordoba (Spain), $8^{\text {th }}$ to $10^{\text {th }}$ April, 2014

Renewable Energy and Power Quality Journal (RE\&PQJ)

ISSN 2172-038 X, No.12, April 2014

\title{
Voltage Control and Power System Stability Enhancement using UPFC
}

\author{
Vireshkumar Mathad $^{1}$, Basanagouda F. Ronad ${ }^{2}$, Suresh H. Jangamshetti ${ }^{3}$ \\ PG-Power and Energy Systems, Department of Electrical and Electronics Engineering \\ Basaveshwar Engineering College (Autonomous), \\ Bagalkot-587103, Karnataka, India. \\ vireshmathad@gmail.com, basugouda.ronad@gmaiil.com, jangam@ rocketmail.com
}

\begin{abstract}
This paper presents application of UPFC in improving the voltage profile and enhancement of the power system stability. Five bus test system is considered for investigating the effect of UPFC. MATLAB Simulink models of test system and UPFC are developed. In Five bus test system UPFC is incorporated between the bus 1 and 4 . Two case studies are taken up; where faults created at two different locations i.e. Bus 4 and 5. For both cases the faults are applied at 1 second and cleared at 1.5 second. Results reveal that, without UPFC, rotor angle oscillations increased in generator and lost synchronism. With UPFC system oscillations damped in 6 seconds and system remained stable. Voltage profile of all 5 buses and rotor angle variations at both generators are analyzed. Thus, it is observed that the stability of system can be improved and voltage profiles flatten significantly with incorporating UPFC.
\end{abstract}

Key words: UPFC, Voltage Profile, Power System Stability, PWM.

\section{Introduction}

Power system stability is broadly defined as a property of power system that enables it to remain into a state of operating equilibrium under normal operating conditions and to retain acceptable state of equilibrium after being subjected to a disturbance [1-2]. This primitive definition of stability requires that the system oscillations should be damped and voltage profile has to be flattened. The continuing rapid development of high-power semiconductor technology makes it possible to control electrical power systems by means of power electronic devices [1].

FACTS (Flexible Alternating Current Transmission Systems) are evolving technology, whose first concept was introduced by N.G Hingorani, in 1988 [6-7]. The technological advances in power semiconductors are permitting the development of devices that react more like an ideal switch and totally controllable. FACTS has number of benefits, such as greater power flow control, increased secure loading of existing transmission lines, damping of power oscillations, less environmental impact and potentially less cost than most alternative techniques of transmission system reinforcement.

The UPFC is the most versatile of the FACTS devices. It performs the functions of the static synchronous compensator (STATCOM), thyristor switched capacitor (TSC) thyristor controlled reactor (TCR), and the phase angle regulator. Further, it also provides additional flexibility by combining some of the functions of the said controllers. The main function of the UPFC is to control the flow of real and reactive power by injecting voltage in series with the transmission line. Both the magnitude and the phase angle of the voltage can be varied independently. Real and reactive power control allows power flow in prescribed routes and loading of transmission lines closer to their thermal limits. UPFC's are also used for improving transient and small signal stability of the power system. The schematic of the UPFC is shown in Fig.1. [1-3]

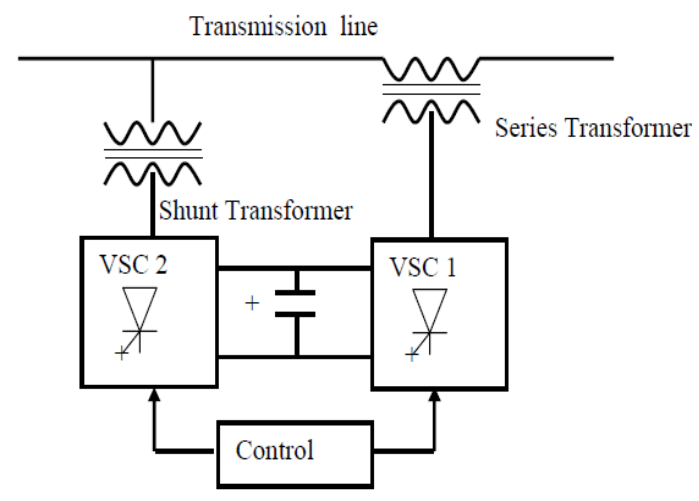

Fig. 1: Schematic diagram of UPFC [1]

UPFC consists of two branches. The series branch includes a voltage source converter, which injects a voltage in series through a transformer. The inverter at the input end of the UPFC is connected in shunt to the AC power system and the inverter at the output end is connected in series with the transmission circuit. Since the series branch can inject a voltage with variable magnitude and phase angle, it can exchange real power with the 
transmission line. However the UPFC as a whole cannot supply or absorb real power in steady state unless it has a power source at its DC terminals.

\section{Methodology}

The performance of UPFC is analyzed with Five-bus test system shown in Fig. 2.

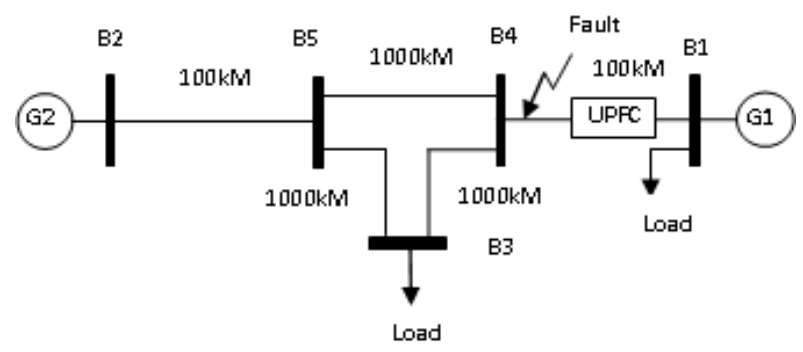

Fig. 2: Five bus test system configuration

UPFC is incorporated at line 1-4 and analyzed for the fault conditions. Test system has two generators: Generator 1 is connected at bus 1 and Generator 2 is connected at bus 2 . System data are given in appendix.

\section{A. Unified Power Flow Controller (UPFC)}

Fig. 3 shows the simulink model of UPFC. It consists of converter 1 , converter 2, three phase PWM inverter, series transformer and shunt transformer. Both converters are operated from a common dc link with a dc storage capacitor. The real power can freely flow in either direction between two-ac branches. Each converter can independently generate or absorb reactive power at the ac output terminals.

Control unit provides gating signals to both converters to provide the desired series voltages and simultaneously drawing necessary shunt currents. AC terminals of which are connected in parallel with the transmission line via a three phase star-delta transformer.

UPFC is placed in series with transmission line through series transformer. For each of the control unit, a simulation model is developed, which includes the pulse width modulation unit. The simulation model of Five bus test system including UPFC is shown in Fig. 4.

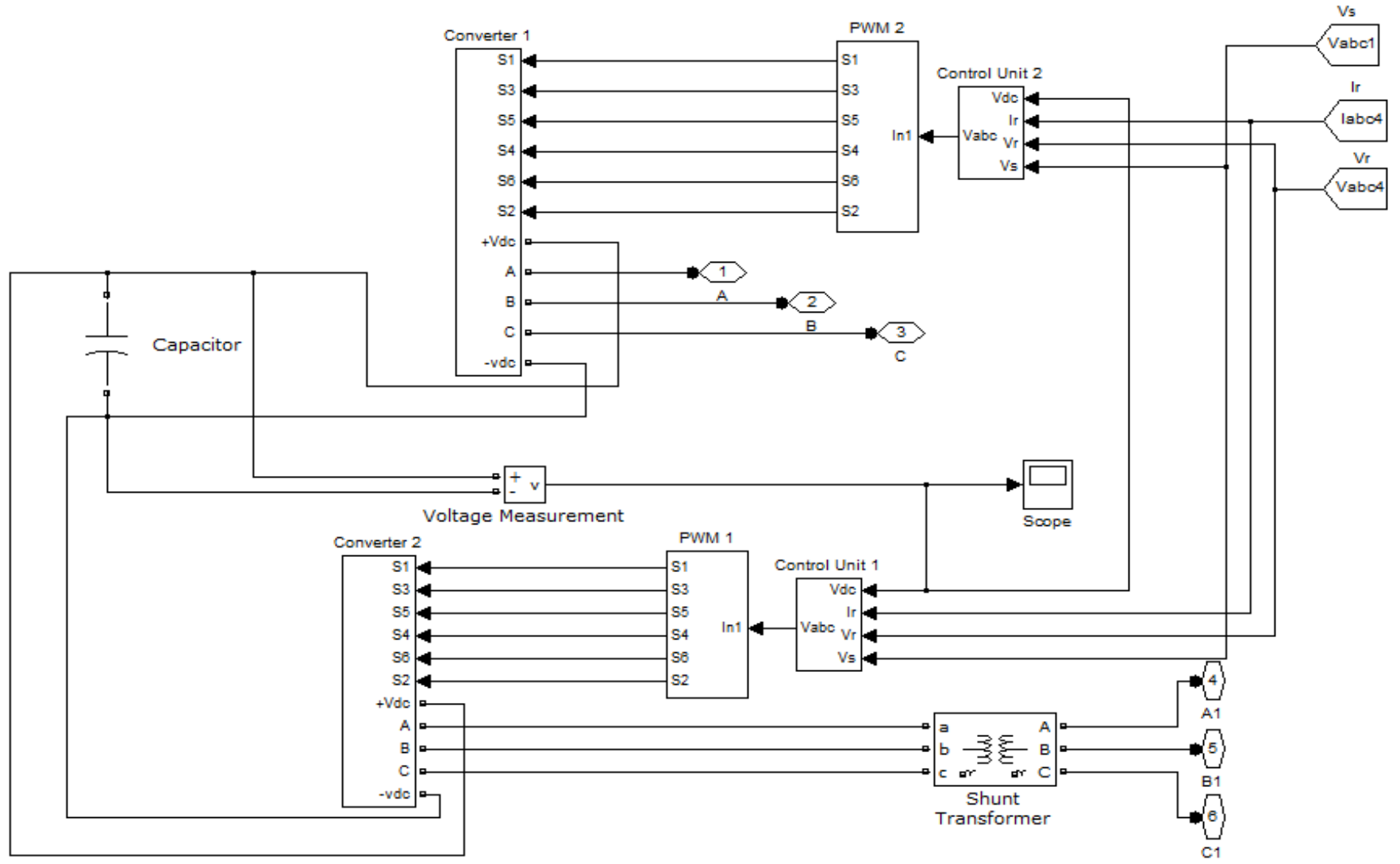

Fig. 3: Simulink model of UPFC 


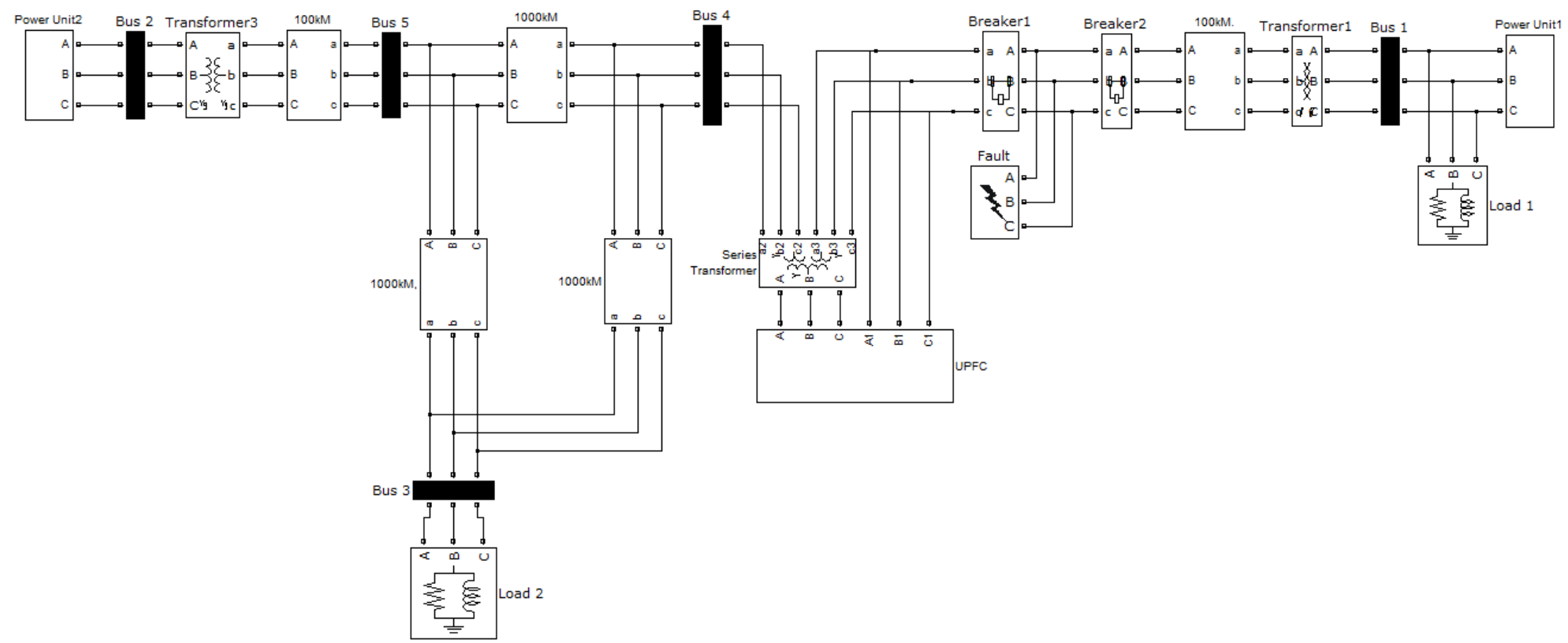

Fig. 4: Simulation circuit of Five bus system with UPFC

\section{B. Control Unit}

Fig. 5. shows DC voltage control circuit of UPFC. DC link voltage is measured $\left(\mathrm{V}_{\mathrm{dc}}\right.$ Measured $)$ and compared with reference value $\left(\mathrm{V}_{\mathrm{dc} \text { Ref }}\right)$, the error is fed to PI controller and related quadrature axis voltage, $\mathrm{V}_{\mathrm{q}}$ is developed. $\mathrm{I}_{\mathrm{d}}$ and $\mathrm{V}_{\mathrm{q}}$ are obtained through Park's transformation of transmission line current and transmission voltage respectively.

Similarly, AC voltage from sending end bus feeding shunt coupling transformer is measured in p.u ( $\left.\mathrm{V}_{\mathrm{AC} \text { Measured }}\right)$ and compared with $\mathrm{AC}$ voltage set point $\mathrm{V}_{\mathrm{AC}}$ Ref $(1.0 \mathrm{p} . \mathrm{u})$, and error is fed to PI controller to generate the related direct axis voltage, $\mathrm{V}_{\mathrm{d}}$. Fig. 6 shows the AC voltage control circuit.

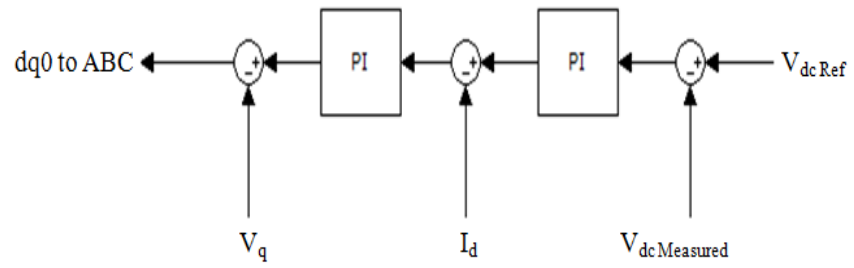

Fig. 5: DC Voltage control circuit.

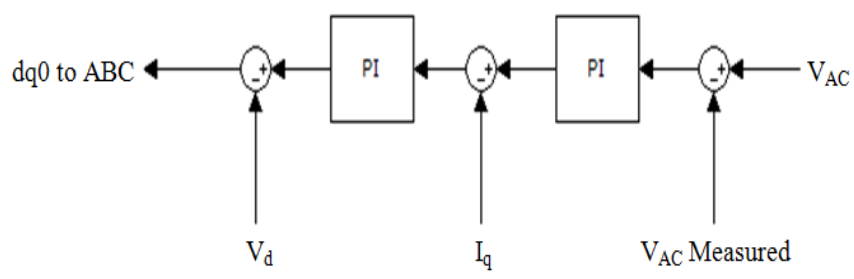

Fig. 6: AC Voltage control circuit.

\section{Pulse Width Modulation (PWM)}

The PWM unit generates pulses for carrier-based PWM converters using two-level topology. The fig.7 shows PWM unit for converter circuits.

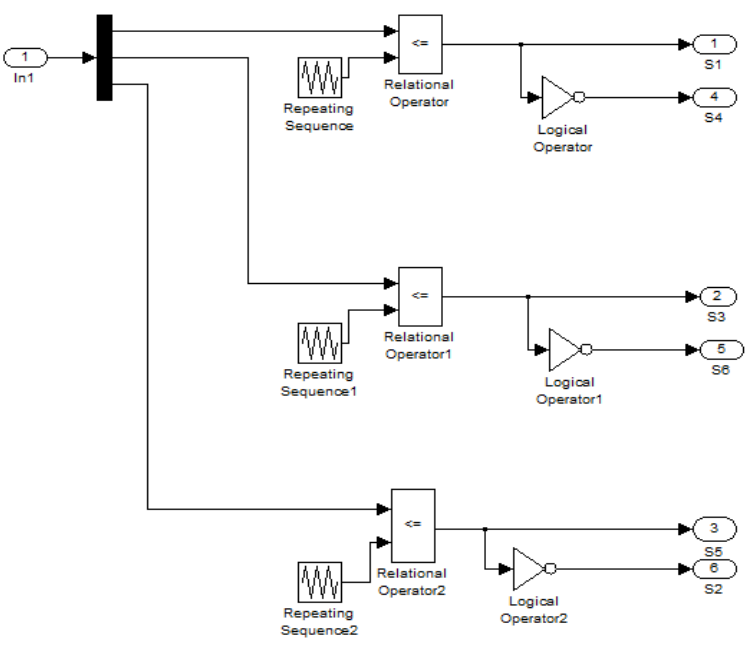

Fig. 7: PWM Sub module for converters.

The unit can be used to fire the forced-commutated devices (FETs, GTOs, or IGBTs) of single-phase, two-phase, threephase, two-level bridges or a combination of two three-phase bridges. The pulses are generated by comparing a triangular carrier waveform to a reference modulating signal. The modulating signals can be generated by the PWM generator itself, or can be a vector of external signals connected at the input of the block. Three reference signals are used to generate the pulses for a three-phase circuit. The pulses generated by control unit are compared with a triangular carrier waveform with a frequency of $10 \mathrm{kHz}$. 


\section{Results and Discussions}

The performance of UPFC is analyzed by applying fault at two different locations.

\section{CASE 1: Fault Applied at bus 4}

Phase to ground fault is applied at bus 4 and the following three conditions are considered for analysis.

$0 \leq \mathrm{t} \leq 1$ Pre Fault condition.

$1 \leq \mathrm{t} \leq 1.5$ During Fault conditions (line 1-4).

$\mathrm{t}>1.5$ Post fault condition.

With these conditions, the behavior of Five bus test system, with and without including the UPFC is examined.

\section{Load Angle Deviation}

Fig. 8 shows the rotor angle deviation of generator 1 with and without UPFC. When fault is applied at bus 4 the rotor angle of Generator 1 starts oscillating and gets deviated. Without UPFC, the oscillations are not settling down and hence lose the stability. While in case of UPFC, rotor angle recovers quickly from deviated value and regains synchronism within $6 \mathrm{Sec}$.

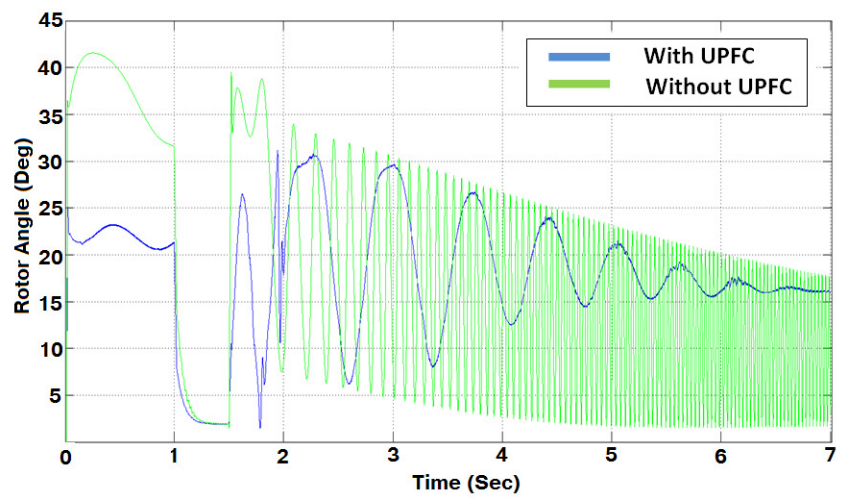

Fig. 8: Load angle deviation for generator 1

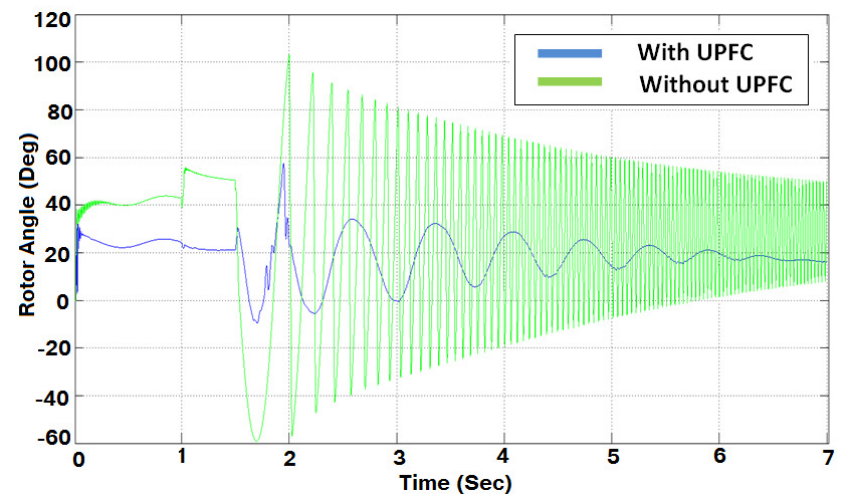

Fig. 9: Load angle deviation for generator 2

Fig. 9 shows the rotor angle deviation of generator 2 which is away from the fault location. Hence amplitude of oscillations are minimum, compared to Generator 1.

\section{Voltage Profile}

Voltage profiles are drawn with and without UPFC for bus 1 and 4. Without UPFC voltages are crossing the limits of deviation. The results shows that voltage deviations are suppressed by UPFC and profile has been flattened in both buses.

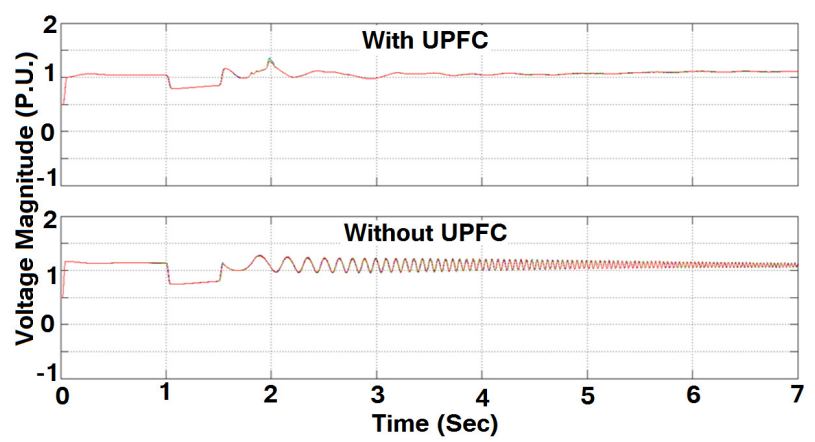

Fig. 10: Bus Voltage Magnitudes with and without UPFC at Bus 1

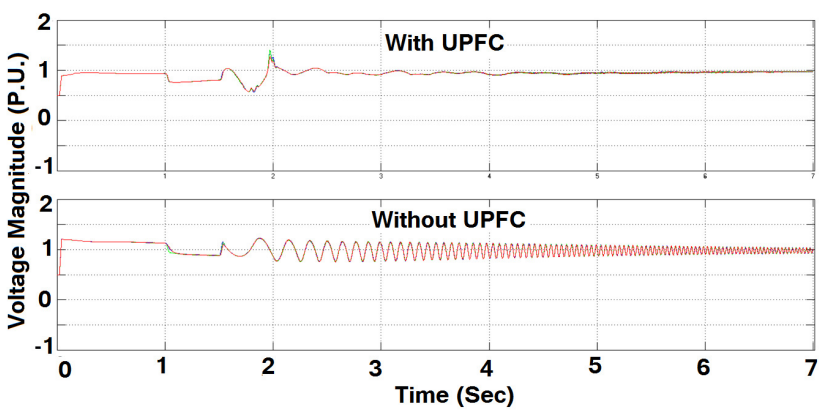

Fig.11: Bus Voltage Magnitudes with and without UPFC at Bus 4

Fig. 12 shows DC link capacitor voltage of UPFC. It is observed that, capacitor voltage starts decreasing as fault occurs. At $1.5 \mathrm{sec}$ fault is cleared and capacitor starts charging. Because of rotor angle fluctuations the $\mathrm{dc}$ capacitor voltage also fluctuates. Capacitor voltage becomes constant when the rotor angle becomes steady.

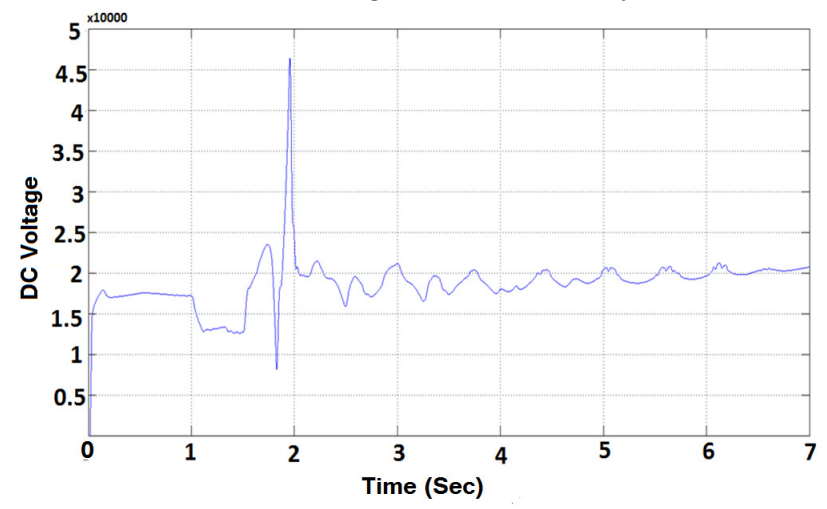

Fig. 12: The DC link capacitor voltage of the UPFC

CASE 2: Fault Applied at Bus 5

Fault is applied at bus 5 and behavior of bus test system with and without UPFC is examined for rotor angle deviation.

Fig. 13 shows rotor angle deviation of Generator 1 . As the fault is away from Generator1, rotor angle oscillations are damped in $4.1 \mathrm{sec}$, much earlier than oscillations of Generator 2.

Fig. 14 shows rotor angle deviation of generator 2 . It is noticed that rotor angle is settled at approximately $5.2 \mathrm{sec}$. 


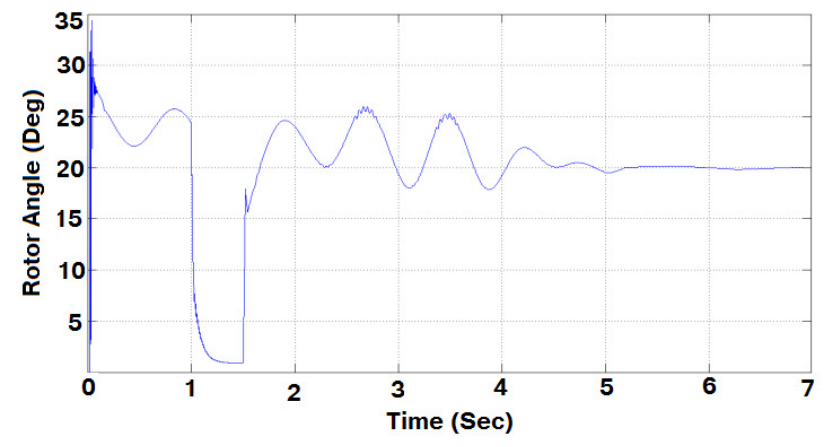

Fig. 13: Load angle deviation for generator 1 (Fault at bus 5)

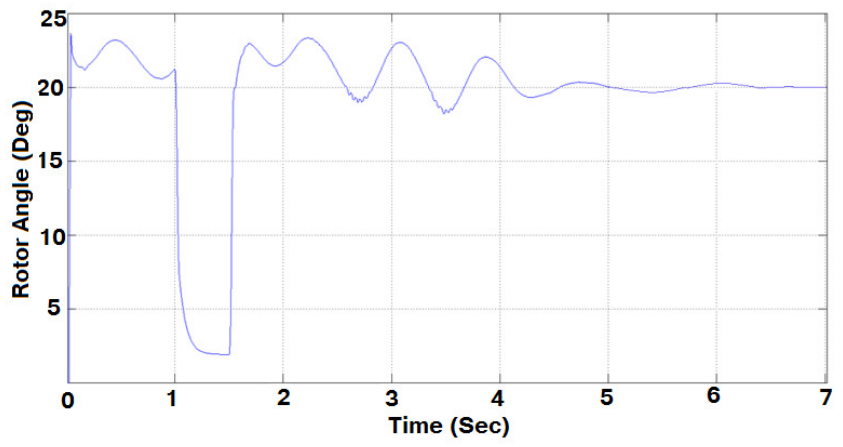

Fig. 14: Load angle deviation for generator 2 (Fault at bus 5)

The voltage profile of bus 4 show that the voltage deviations are suppressed by UPFC and profile have been flattened.

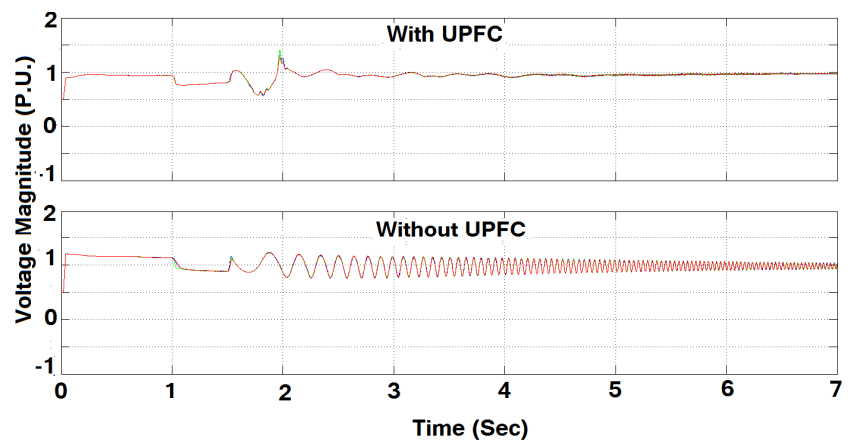

Fig. 15: Bus Voltage Magnitudes with and without UPFC at Bus 4

\section{Conclusion}

Voltage profile improvement and stability enhancement of power system using UPFC is presented in the paper. Simulink models of Five bus test system and UPFC are developed. The test system was analyzed with and without incorporating UPFC. Two cases studies were taken up, where faults occurred at two buses i.e $4^{\text {th }}$ and $5^{\text {th }}$. For both cases the faults were created at 1 second and cleared at 1.5 second. It was observed that the oscillations of rotor angle in generator, which is near to fault, increased and lost synchronism. In other generator rotor angle sustained for 30 seconds. Further, UPFC was incorporated in test system at line 1-4 and analyzed for the fault conditions. Results revealed that system oscillations were damped at $6 \mathrm{sec}$. Voltage profile of all five buses and rotor angle violations at both generators were drawn. Thus, it was concluded that stability of power system and voltage profiles improves with incorporation of UPFC.

\section{References}

[1] N. G. Hingorani and L. Gyugyi, "Understanding FACTS: Concepts and Technology of Flexible AC Transmission Systems", New York: IEEE Press, 2000.

[2] P. Kundur, "Power system stability and control", McGrawHill New York, 2000, pp: 17-40.

[3] Xiao-Ping Zhang, Christian Rehtanz and Bikash Pal, "Flexible AC Transmission Systems Modeling and Control", Germany, 2006.

[4] A. Elkholy, F. H. Fahmy, A. A. Abou El-Ela, "Power System Stability Enhancement using The Unified Power Flow Controller" Proceedings of the 14th International Middle East Power Systems Conference (MEPCON'10), Cairo University, Egypt, December 19-21, 2010, Paper ID 240.

[5] S. Tara Kalyani, G. Tulasiram Das, "Simulation of D-Q Control System for A Unified Power Flow Controller", ARPN Journal of Engineering and Applied Sciences, VOL. 2, NO. 6 , December 2007 ISSN 1819-6608.

[6] Vireshkumar G. Mathad, Basangouda F. Ronad, Suresh H. Jangamshetti, "Review on Comparison of FACTS Controllers for Power System Stability Enhancement" International Journal of Scientific and Research Publications, Volume 3, Issue 3, March 2013,ISSN 2250-315.

[7] Banakar Basavaraj, Ronad Basangouda, Jangamshetti Suresh. H., "Transmission Loss Minimization using UPFC", International Journal of Modern Engineering Research (IJMER), Vol. 2, Issue. 5, Sep.-Oct. 2012 pp- 3602-3606 ISSN: 2249-6645.

[8] K. R. Padiyar, A. M. Kulkarni, "Control Design and Simulation of Unified Power Flow Controller", IEEE Transaction on Power Delivery, Vol. 13, No. 4, October 1998, pages(s) 1348-1354.

\section{APPENDIX}

\begin{tabular}{|l|l|}
\hline Generator 1 & $520 \mathrm{MVA}, 15.75 \mathrm{kV}, 50 \mathrm{~Hz}$ \\
\hline Generator 2 & $390.7 \mathrm{MVA}, 15 \mathrm{kV}, 50 \mathrm{~Hz}$ \\
\hline $\begin{array}{l}\text { Generator 1 and 2 } \\
\text { parameters in per unit: }\end{array}$ & $\begin{array}{l}\mathrm{X}_{\mathrm{d}}=1.305, \mathrm{X}_{\mathrm{q}}=0.474, \mathrm{X}_{\mathrm{d}}=.296, \\
\mathrm{X}_{\mathrm{q}}=0.243, \mathrm{R}_{\mathrm{s}}=2.8544 \mathrm{e}^{-3}, \mathrm{H}=3.7\end{array}$ \\
\hline $\begin{array}{l}\text { Exciter parameters in } \\
\text { per unit: }\end{array}$ & $\begin{array}{l}\mathrm{K}_{\mathrm{A}}=200, \mathrm{~T}_{\mathrm{A}}=0.001, \mathrm{~T}_{\mathrm{E}}=0, \\
\mathrm{~K}_{\mathrm{E}}=1, \mathrm{~K}_{\mathrm{F}}=0.001, \mathrm{~T}_{\mathrm{F}}=0.1, \\
\mathrm{~T}_{\mathrm{R}}=0.02\end{array}$ \\
\hline $\begin{array}{l}\text { UPFC parameters in } \\
\text { per unit: }\end{array}$ & $\mathrm{K}_{\mathrm{p}}=0.96, \mathrm{~K}_{\mathrm{i}}=0.79, \mathrm{C}=330 \mathrm{e}^{-4}$ \\
\hline Series Transformer & $\begin{array}{l}520 \mathrm{MVA}, 354.9 / 15 \mathrm{kV}, 50 \mathrm{~Hz} \\
\mathrm{R}_{1}=\mathrm{R}_{2}=\mathrm{R}_{3}=0.002 \mathrm{pu} \\
\mathrm{L}_{1}=\mathrm{L}_{2}=\mathrm{L}_{3}=0.002 \mathrm{pu}\end{array}$ \\
\hline Shunt Transformer & $\begin{array}{l}100 \mathrm{MVA}_{1} 15 / 354.9 \mathrm{kV}, 50 \mathrm{~Hz} \\
\mathrm{R}_{1}=\mathrm{R}_{2}=0.002 \mathrm{pu} \\
\mathrm{L}_{1}=\mathrm{L}_{2}=0.002 \mathrm{pu}\end{array}$ \\
\hline
\end{tabular}

